\title{
Allicin induces apoptosis of the MGC-803 human gastric carcinoma cell line through the p38 mitogen-activated protein kinase/caspase-3 signaling pathway
}

\author{
XUECHENG ZHANG ${ }^{1}$, YONG ZHU ${ }^{2}$, WEI DUAN ${ }^{1}$, CHEN FENG $^{1}$ and XUAN HE ${ }^{1}$ \\ ${ }^{1}$ Department of Oncology, Shaanxi Corps Hospital, Chinese People's Armed Police Forces, \\ Xi'an, Shaanxi 710054; ${ }^{2}$ Department of Radiotherapy, Central Hospital of Baoji, \\ Xi'an, Shaanxi 721000, P.R. China
}

Received February 4, 2014; Accepted November 3, 2014

DOI: $10.3892 / \mathrm{mmr} .2014 .3109$

\begin{abstract}
Gastric cancer is one of the most common forms of malignant tumor, and the development of anti-gastric cancer drugs with minimal toxicity is of clinical importance. Allicin is extracted from Allium sativum (garlic). Recent research, including clinical experiments, has shown that garlic has anticancer and tumor suppressive effects. The present study aimed to investigate the effects of allicin on the MGC-803 human gastric carcinoma cell line, and to further explore the possible mechanisms of its tumor suppressor effects. The effects of allicin on the MGC- 803 cells were initially examined using an 3-(4,5-dimethylthiazol-2-yl)-2,5-diphenyltetrazolium bromide assay. Hoechst staining was also used, in order to demonstrate the impact of allicin on MGC-803 cell apoptosis. In addition, western blot analysis was performed to determine the abnormal expression levels of apoptosis-associated proteins, following the treatment of MGC-803 cells with allicin. Western blotting was also used to investigate the specific mechanisms underlying allicin-induced apoptosis of MGC- 803 cells. The rate of MGC-803 apoptosis was significantly increased, when the concentration and treatment time of allicin were increased. Hoechst staining detected an enhanced rate of apoptosis, and enhanced expression levels of cleaved caspase 3 were determined by western blotting. Notably, the protein expression levels of $\mathrm{p} 38$ were increased when the MGC-803 cells were treated with allicin. The results of the present study suggest that allicin may inhibit the proliferation and induce the apoptosis of MGC-803 human gastric carcinoma cells, and this
\end{abstract}

Correspondence to: Professor Xuecheng Zhang, Department of Oncology, Shaanxi Corps Hospital, Chinese People's Armed Police Forces, 88 Southeast Ring, Xi'an, Shaanxi 710054, P.R. China E-mail: zhangxuechengprc@163.com

Key words: p38 mitogen-activated protein kinase/caspase-3, allicin, gastric carcinoma, apoptosis, may partially be achieved through the enhanced expression of p38 and cleaved caspase 3 .

\section{Introduction}

Gastric cancer is one of the most common malignancies in China (1). Increasing numbers of people succumb to gastric cancer each year, and gastric cancer accounts for $~ 25 \%$ of all cancer-associated mortality (2). Furthermore, the number of new patients diagnosed with gastric cancer is increasing annually $(2,3)$, and it is therefore considered a serious threat to public health. Gastric cancer may occur at any age, with the majority of patients aged between 40 and 60 years old (3). Currently, the cause of gastric cancer is unknown and may be associated with numerous factors, such as diet, lifestyle, environmental factors, genetic predisposition, mental factors and Helicobacter pylori infection (4). Comprehensive therapy including chemotherapy is currently the main method used for treatment of advanced gastric cancer; however, chemotherapeutic drugs may not only kill tumor cells, but also damage normal tissue cells. Therefore, the overall survival of gastric cancer patients has not significantly improved (5). To maximize the effects of cytotoxicity to malignant tumor cells, research has recently focused on pharmaceutical drugs with the lowest normal cell toxicity $(3,6)$.

Allicin is an organic sulfur compound from the bulbs of Allium sativum, which is also present in onions and other Alliaceae plants. Allicin has strong antibacterial and anti-inflammatory effects, and may inhibit the growth of or kill various bacteria, fungi and viruses (2). A previous epidemiological study demonstrated the antitumor activity of allicin (1), and allicin has been shown to directly kill tumor cells, inhibit tumor cell proliferation and induce apoptosis (7). Previous studies have shown that allicin may significantly induce apoptosis in $\mathrm{LNCaP}$ prostate cancer cells, mouse melanoma cells, and SGC-7901 human gastric adenocarcinoma cells $(7,8)$. In addition, allicin may stimulate the immune system to release more active factors, which could inhibit the growth of tumor cells through enhancement 
of its anticancer effects $(3,7)$. As compared with traditional chemotherapy drugs, in the clinical treatment of tumors allicin not only has no toxic effects on the body, but may also stimulate the body to release various cytokines and enhance immune resistance $(5,9)$.

The process by which allicin induces apoptosis of tumor cells is precisely regulated, and numerous proteins are involved. The present study aimed to explore the specific mechanisms of the pro-apoptotic effects of allicin on the proliferation and apoptosis of the MGC-803 gastric carcinoma cell line, which may provide information on the clinical application of allicin for the treatment of gastric cancer.

\section{Materials and methods}

Human samples and cell lines. The MGC-803, BGC-823 and SGC-7901 human gastric carcinoma cell lines were purchased from the American Type Tissue Culture Collection (Manassas, VA, USA). The cells were cultured in Dulbecco's modified Eagle's medium (DMEM)/F12 (Hyclone Laboratories, Inc., Logan, UT, USA), supplemented with $10 \%$ fetal bovine serum (Hyclone Laboratories, Inc.), $100 \mathrm{U} / \mathrm{ml}$ penicillin and streptomycin (Sigma-Aldrich, St. Louis, MO, USA), in $25-\mathrm{cm}^{2}$ culture flasks at $37^{\circ} \mathrm{C}$ in a humidified atmosphere containing $5 \% \mathrm{CO}_{2}$.

Cell viability assay. Cell viability was determined using a colorimetric 3-(4,5-dimethylthiazol-2-yl)-2,5-diphenyltetrazolium bromide (MTT) assay (Sigma-Aldrich). In order to determine the impact of allicin on the MGC-803, BGC-823 and SGC-7901 human gastric carcinoma cell lines, the cells were cultured to $\sim 70 \%$ confluence and starved in serum-free DMEM (Life Technologies, Grand Island, NY, USA) overnight. The three cell lines were then incubated with 0.1 , 1 and $10 \mu \mathrm{g} / \mathrm{ml}$ allicin for $48 \mathrm{~h}$. Following treatment with allicin (Sigma-Aldrich) for disease prevention, the cells were cultured in fresh medium including $0.5 \mathrm{mg} / \mathrm{ml} \mathrm{MTT}$, for $4 \mathrm{~h}$. Dimethyl sulfoxide (Sigma-Aldrich) was then added to the wells to dissolve the blue formazan product, and the optical density of the samples was determined spectrophotometrically (Cary 4000; Agilent Technologies, Novato, CA, USA) at a wavelength of $550 \mathrm{~nm}$. To determine whether the effects of allicin were time-dependent, the cells were preincubated with $1 \mu \mathrm{g} / \mathrm{ml}$ allicin for 12,24 or $48 \mathrm{~h}$ and cell viability was determined using the same method as previously described. Each experiment was independently performed at least three times.

Hoechst 33258 staining. The MGC-803, BGC-823 and SGC-7901 human gastric carcinoma cells $\left(1 \times 10^{5}\right.$ cells per well) were cultured in six-well tissue culture plates. Once they had reached $70-80 \%$ confluence, the cells were incubated for $16 \mathrm{~h}$ in serum-free DMEM. Following the incubation, $1 \mu \mathrm{g} / \mathrm{ml}$ allicin was added to the fresh media and the cells were incubated for a further $48 \mathrm{~h}$. Following treatment with allicin, the media was removed, and the cells were rinsed three times with cold phosphate-buffered saline (PBS) and fixed with $4 \%$ formaldehyde (Beijing Zhongshan Golden Bridge Biotechnology Co., Ltd., Beijing, China) in PBS for $20 \mathrm{~min}$ at room temperature. The cells were then washed three times with cold PBS and stained with Hoechst 33258 (10 $\mu \mathrm{g} / \mathrm{ml}$; Sigma-Aldrich) for $5 \mathrm{~min}$. After staining, the cells were further washed with cold PBS and examined under a fluorescence microscope (Agilent 1200; Agilent Technologies).

Western blot analysis. The three cell lines, MGC-803, BGC-823 and SGC-7901 were used for western blot analysis. The cells were initially lysed using radioimmunoprecipitation assay buffer [Beijing Solarbio Science \& Technology Co., Ltd., Beijing, China; $50 \mathrm{mM}$ Tris/HCl, pH 7.4, $150 \mathrm{mM}$ $\mathrm{NaCl} 1 \%(\mathrm{v} / \mathrm{v}) \mathrm{NP}-40,0.1 \%(\mathrm{w} / \mathrm{v}) \mathrm{SDS}$ ] containing $1 \%(\mathrm{v} / \mathrm{v})$ PMSF (Beijing Solarbio Science \& Technology Co., Ltd.), $0.3 \%(\mathrm{v} / \mathrm{v})$ protease inhibitor (Sigma-Aldrich) and $0.1 \%(\mathrm{v} / \mathrm{v})$ phosphorylated proteinase inhibitor (Sigma-Aldrich). The lysates were then centrifuged at $4,000 \mathrm{xg}$ at $4^{\circ} \mathrm{C}$ for $15 \mathrm{~min}$, in order to collect the supernatants. To quantify the relative concentration of the total protein samples, a Bicinchoninic Acid Protein Assay kit (Pierce Biotechnology, Inc., Rockford, IL, USA) was used. Equal quantities of protein $(15 \mu \mathrm{g})$ were separated on a $10 \%$ SDS-PAGE gel, and then transferred onto polyvinylidene fluoride (PVDF) membranes (General Electric Company, New York City, NY, USA) at $300 \mathrm{~mA}$ for $2 \mathrm{~h}$. In order to block non-specific binding proteins, the PVDF membranes were blocked using $8 \%(\mathrm{w} / \mathrm{v})$ milk in Tris-buffered saline with Tween ${ }^{\circledR}$, for $2 \mathrm{~h}$ at room temperature. The membranes were then incubated with primary antibodies (1:1,000; Cell Signaling Technology, Inc., Danvers, MA, USA) targeting $\beta$-actin (\#4967; rabbit polyclonal synthetic peptide), cleaved caspase 3 (\#9661; rabbit polyclonal synthetic peptide), p-p38 (\#9212; rabbit polyclonal synthetic peptide), caspase-3 (\#9661; rabbit polyclonal synthetic peptide), Bax (\#2774; rabbit polyclonal synthetic peptide), Bcl (\#2872; rabbit polyclonal synthetic peptide) and p38 (\#9212, rabbit polyclonal synthetic peptide) overnight at $4^{\circ} \mathrm{C}$. The membranes were washed four times with PBS-Tween ${ }^{\circledR}(5 \mathrm{~min} / \mathrm{time})$, and then incubated with horseradish peroxidase-conjugated goat anti-rabbit immunoglobulin G (Abmart, Inc., Shanghai, China; 1:5,000 dilution), for $2 \mathrm{~h}$ at room temperature. Following the incubation, the membranes were washed four times ( $5 \mathrm{~min} / \mathrm{time})$. The blots were visualized using an Enhanced Chemiluminescence substrate (EMD Millipore, Billerica, MA, USA), according to the manufacturer's instructions. The relative protein expression levels were then determined and quantified using Bandscan 4.30 (Glyko Biomedical, Novato, CA, USA). In order to quantify changes to protein expression, the target protein was normalized against $\beta$-actin.

Apoptosis assay. To detect the effects of allicin on the rate of apoptosis of MGC-803 cells BGC-823 and SGC-7901, the cells that had reached $50-60 \%$ confluence were treated with $0.1,1$ or $10 \mu \mathrm{g} / \mathrm{ml}$ allicin for $48 \mathrm{~h}$. Following the treatment with allicin, the cells were washed three times with 1X PBS. The Annexin V-fluorescein isothiocyanate (FITC)-propidium iodide (PI) Apoptosis kit (Invitrogen Life Technologies, Carlsbad, CA, USA) was then used to determine the rate of apoptosis by flow cytometry. This assay employs fluorescein-labeled Annexin V in conjunction with PI, to detect cells undergoing apoptosis. Briefly, the cells were washed three times with 1X PBS and suspended at 2-3x10 $10^{6}$ cells $/ \mathrm{ml}$ in $1 \mathrm{X}$ Annexin V Binding Buffer (10 mM HEPES/NaOH, pH 7.4; $140 \mathrm{mM} \mathrm{NaCl}$ and $2.5 \mathrm{mM} \mathrm{CaCl}_{2}$ ). Annexin V-FITC and PI Buffer were then 


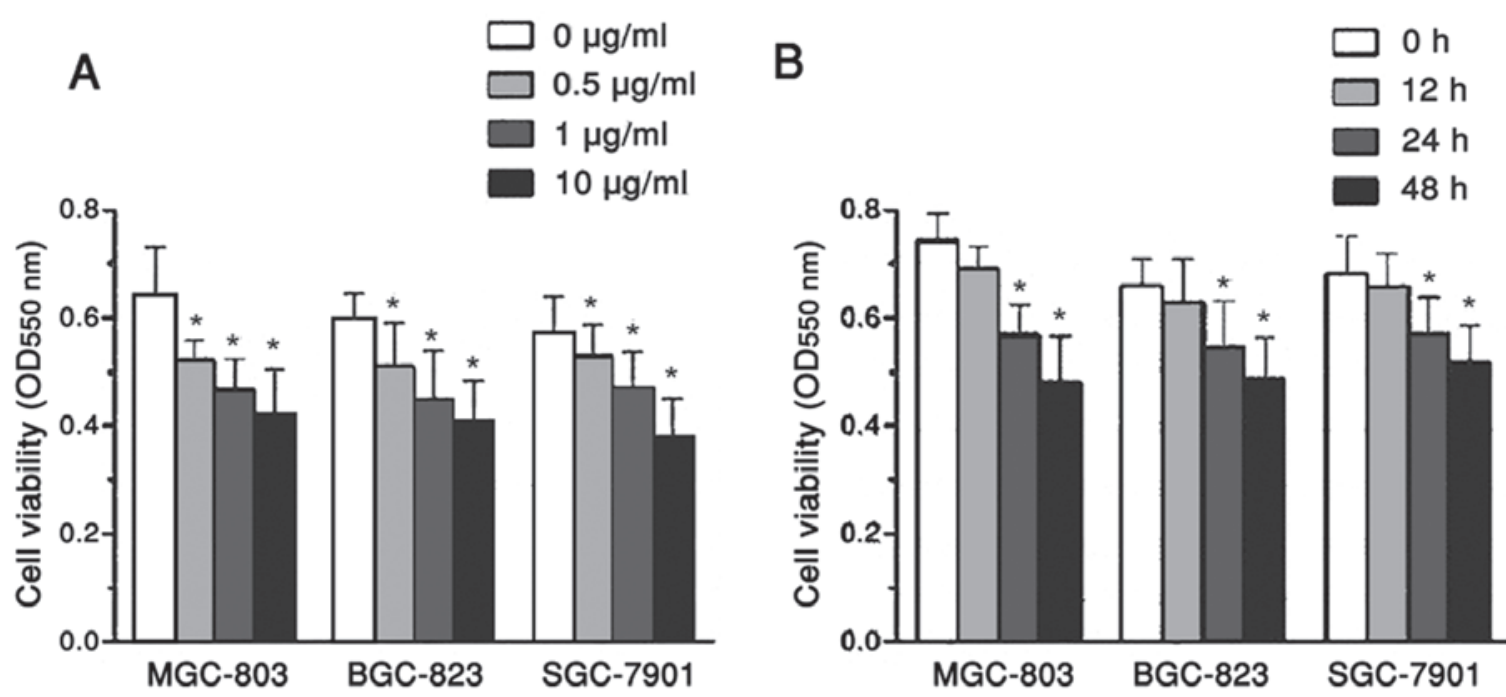

Figure 1. MGC-803, BGC-823 and SGC-7901 human gastric carcinoma cell viability was affected by treatment with allicin in a dose- and time-dependent manner. (A) MGC-803, BGC-823 and SGC-7901 cells were exposed to $0.1,1$, and $10 \mu \mathrm{g} / \mathrm{ml}$ allicin for $48 \mathrm{~h}$. (B) MGC-803, BGC-823 and SGC-7901 cells were treated with $1 \mu \mathrm{g} / \mathrm{ml}$ allicin for 12,24 and $48 \mathrm{~h}$. Cell viability was determined by a 3-(4,5-dimethylthiazol-2-yl)-2,5-diphenyltetrazolium bromide assay, and the optical density (OD) of the cells was measured at $550 \mathrm{~nm}$ using a spectrophotometer. Data are represented as the mean \pm standard error of the mean, $\mathrm{n}=6$ independent experiments. ${ }^{*} \mathrm{P}<0.05$ versus control.

added to the cells, which were incubated at room temperature for $15 \mathrm{~min}$ in the dark. The untreated cells were used as an internal control. Following incubation, the cells were filtered using a filter screen and the cells were analyzed by flow cytometry (BD FACSVerse ${ }^{\mathrm{TM}}$, BD Biosciences, Franklin Lakes, NJ, USA) within $1 \mathrm{~h}$ of staining using the FL1 (FITC) and FL3 (PI) lines.

Statistical analysis. The data are expressed as the mean \pm standard error of the mean. The number of independent experiments is represented by ' $n$ '. Multiple comparisons were performed using one-way analysis of variance, followed by Tukey's multiple-comparison test. Statistical analyses were performed using PASW Statistic 18 (IBM, Armonk, NY, USA). P<0.05 was considered to indicate a statistically significant difference.

\section{Results}

MGC-803, BGC-823 and SGC-7901 cell viability is affected by allicin in a dose-and time-dependent manner. To investigate the impact of allicin on cell viability, the MGC-803, BGC-823 and SGC-7901 human gastric carcinoma cells were treated with $0.1,1$ and $10 \mu \mathrm{g} / \mathrm{ml}$ allicin, for $48 \mathrm{~h}$. Cell viability was then analyzed by an MTT assay. The viability of the MGC-803, BGC-823 and SGC-7901 cells was significantly reduced by $\sim 30 \%$, when the concentration of allicin was increased from 0 to $10 \mu \mathrm{g} / \mathrm{ml}$ (Fig. 1A). Based on these results, $1 \mathrm{mg} / \mathrm{ml}$ allicin was selected for use in follow-up studies. Furthermore, the MGC-803, BGC-823 and SGC-7901 cells were also treated with $1 \mu \mathrm{g} / \mathrm{ml}$ allicin for 12 , 24 and $48 \mathrm{~h}$, and the corresponding cell viability was determined by MTT. The viability of the MGC-803, BGC-823 and SGC-7901 cells was reduced by $\sim 11$ and 16\%, at 24 and $48 \mathrm{~h}$, respectively (Fig. 1B). These results suggest that the viability of human gastric carcinoma cells is significantly reduced in response to treatment with allicin in a dose- and time-dependent manner.
Allicin induces apoptosis of gastric carcinoma cells. Since MGC-803, BGC-823 and SGC-7901 cell viability was significantly inhibited by allicin, the present study examined the correlation between the apoptosis of MGC-803, BGC-823 and SGC-7901 cells, and allicin. Hoechst staining is one of the most common methods used to directly detect cell apoptosis, since it provides vivid morphological results. In the present study, MGC-803, BGC-823 and SGC-7901 cells were treated with $1 \mu \mathrm{g} / \mathrm{ml}$ allicin for $48 \mathrm{~h}$, and then stained with Hoechst 33258. Enhanced cell apoptosis was detected in the cells, in response to incubation with allicin (Fig. 2A). To quantify the rate of apoptosis, an Annexin V-FITC-PI kit was used. Flow cytometry revealed that the number of apoptotic MGC-803, BGC-823 and SGC-7901 cells was increased in response to treatment with allicin, by 87,100 and $132 \%$, as compared with the control group, respectively (Fig. 2B).

Cleaved caspase 3 regulates allicin-induced apoptosis of gastric carcinoma cells. To further explore the effects of allicin on the apoptosis of MGC-803, BGC-823 and SGC-7901 human gastric carcinoma cells, the present study determined the altered expression levels of apoptosis-associated proteins by western blotting. When the MGC-803, BGC-823 and SGC-7901 cells were treated with 0.01, 0.1, 1 and $10 \mu \mathrm{g} / \mathrm{ml}$ allicin for $48 \mathrm{~h}$, the protein expression levels of cleaved caspase 3 were increased in a dose-dependent manner (Fig. 3). Caspase 3 is an inactive zymogen within the body; however, during apoptosis, caspase 3 may be hydrolyzed into an active enzyme (10). Once the expression levels of cleaved caspase 3 are enhanced, cell apoptosis signaling may be activated and protein degradation may occur. The results of the present study indicate that allicin may induce apoptosis of MGC-803, BGC-823 and SGC-7901 cells mainly by enhancing the expression of cleaved caspase 3 . From these data, it may be hypothesized that allicin induces the expression of $\mathrm{p} 38$, which activates caspase 3 , thereby triggering 
A

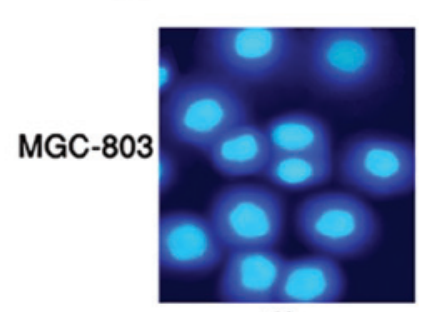

$\mathrm{Oh}$

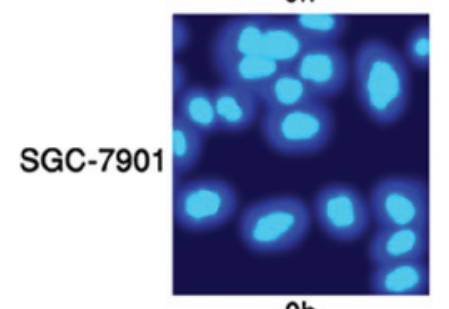

Oh

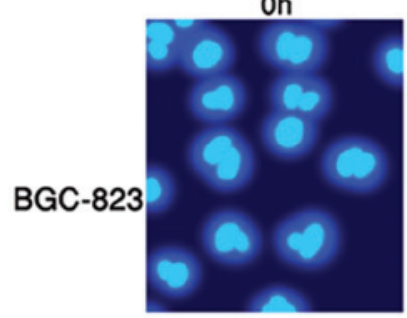

Oh

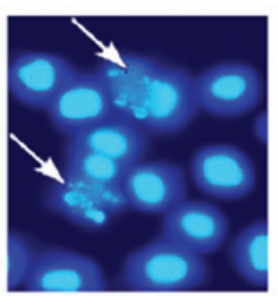

$48 \mathrm{~h}$

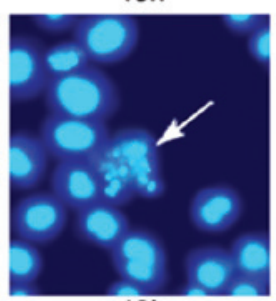

$48 \mathrm{~h}$

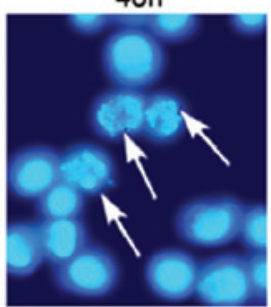

$48 \mathrm{~h}$
B

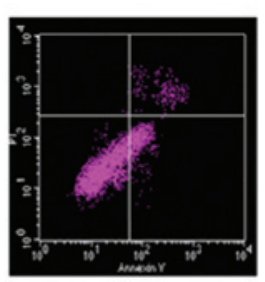

Con

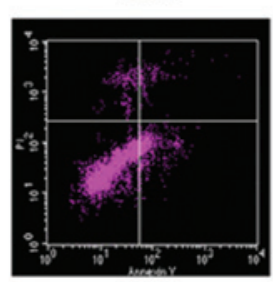

Con

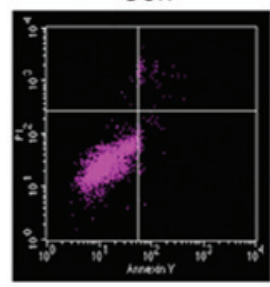

Con

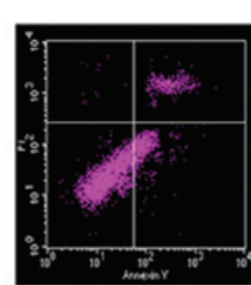

Allicin

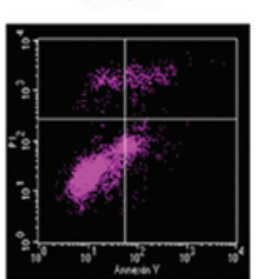

Allicin

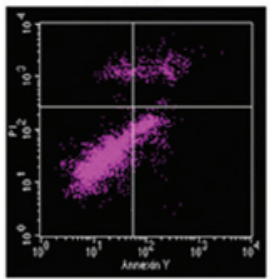

Allicin
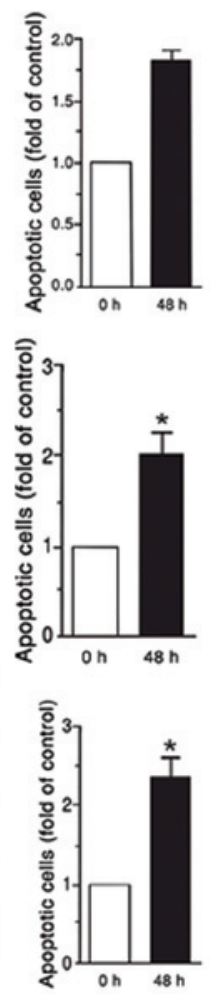

Figure 2. Enhanced apoptosis of MGC-803, BGC-823 and SGC-7901 human gastric carcinoma cells was determined in response to incubation with $1 \mu \mathrm{g} / \mathrm{ml}$ allicin for $48 \mathrm{~h}$. (A) Hoechst 33258 staining demonstrated enhanced cell apoptosis. Arrows indicate apoptotic cells at x40 magnification. (B) Annexin-V fluorescein isothiocyanate and propidium iodide kit was used to detect the rate of cell apoptosis. Data are represented as the mean \pm standard error of the mean, $\mathrm{n}=3$ independent experiments. ${ }^{*} \mathrm{P}<0.05$ versus control (Con).

MGC-803

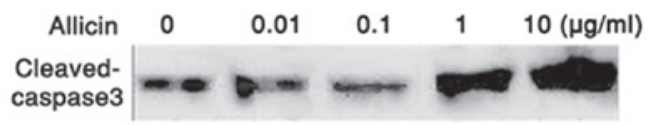

Actin

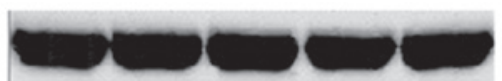

BGC-823

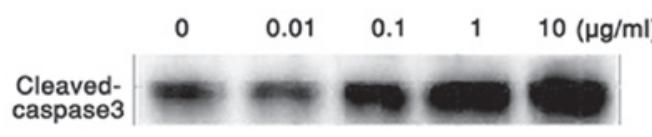

Actin

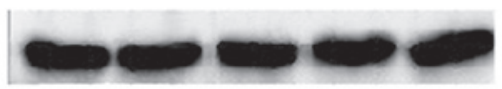

SGC-7901

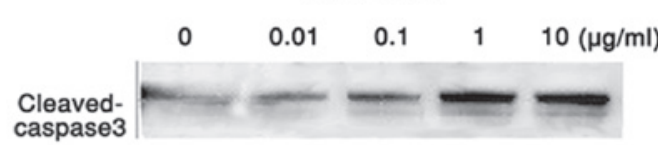

Actin

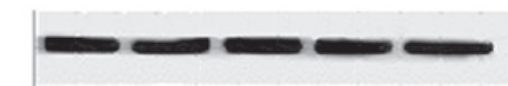

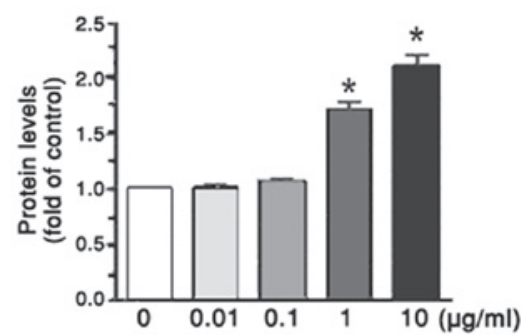
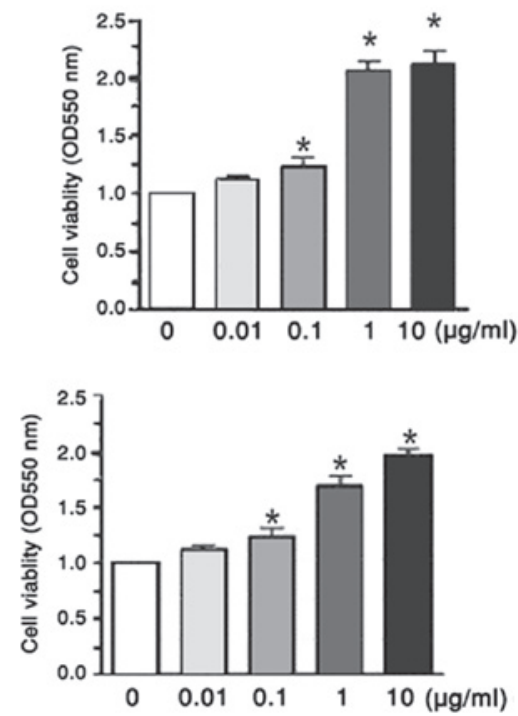

Figure 3. Caspase 3 was activated when the MGC-803, BGC-823 and SGC-7901 human gastric carcinoma cells were treated with $0.01,0.1,1$ and $10 \mu \mathrm{g} / \mathrm{ml}$ allicin for $48 \mathrm{~h}$. Data are represented as the mean \pm standard error of the mean, $\mathrm{n}=3$ independent experiments. " $\mathrm{P}<0.05$ versus control. 

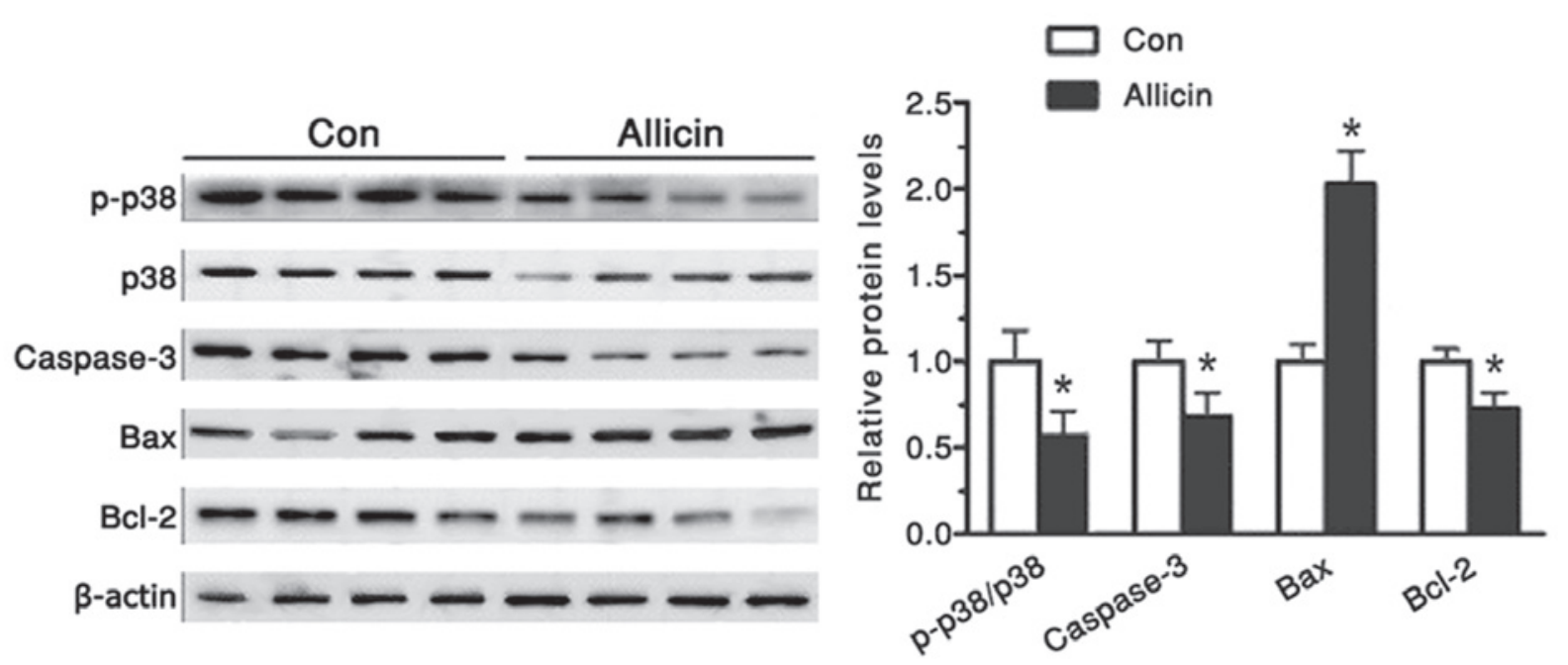

Figure 4. Enhanced p38 protein expression levels correlate with increased cell apoptosis rate. Western blot analysis revealed increased p38 protein expression levels in the MGC-803 cells in response to treatment with an increased concentration of allicin. Data are represented as the mean \pm standard error of the mean, $\mathrm{n}=3$ independent experiments. Con, control; p-p38, phosph-p38. ${ }^{*} \mathrm{P}<0.05$ versus control.

the caspase cascade reaction, inhibiting cell growth and promoting apoptosis.

Increased 38 expression levels promote caspase 3 activation. The p38 mitogen-activated protein kinase (MAPK) signal transduction pathway is an important branch of the MAPK pathway. It has an important role in numerous physiological and pathological processes, including inflammation, stress, apoptosis, cell cycle and growth $(11,12)$. A previous study suggested that it may also be a potential target for tumor treatment (13). Studies have shown that p38 activation leads to increased expression of cleaved caspase 3 and promotes apoptosis $(3,14)$. In the present study, the protein expression levels of p38 were gradually enhanced in the MGC-803 cells, in response to treatment with $1 \mu \mathrm{g} / \mathrm{ml}$ allicin for $48 \mathrm{~h}$ (Fig. 4). Whereas, the protein expression levels of phospho-p38 and caspase 3 were decreased (Fig. 4). The present study also aimed to determine the expression levels of apoptosis-associated proteins, Bcl-2 and Bax. When the cells were treated with allicin, the protein expression levels of Bax were increased nearly one-fold, whereas the protein expression levels of Bcl-2 level were decreased $>35 \%$.

\section{Discussion}

Garlic is the bulb of Allium plants. The main bioactive substance in garlic is considered to be the sulfur compound, which is also known as allicin $\left(\mathrm{C}_{6} \mathrm{H}_{10} \mathrm{~S}_{3}\right)(15)$. A previous study showed that allicin may possess antibacterial and anti-inflammatory effects (16). Furthermore, it has also been shown to inhibit tumor growth, this finding has been demonstrated by clinical and experimental statistics (17). The results of the present study confirm that allicin can inhibit the growth of cancer cells in vitro; however, the underlying mechanism remains unclear (18). Previous research has shown that allicin can induce the apoptosis of cancer cells through the activation of caspase 3, caspase 8 and caspase 9 (14). Notably, as an antitumor drug, allicin exhibits little toxicity towards normal cells and tissues (18). Therefore the present study focused on the effects of allicin on human gastric carcinoma cells, in order to elucidate its potential mechanism.

The MGC-803 cell line is an immortal cell line derived from human gastric carcinoma, which was widely applied in the present gastric cancer study. Furthermore, two other human gastric cancer cell lines, BGC-823 and SGC-7901 were also used. The MGC-803, BGC-823 and SGC-7901 cells were initially treated with different concentrations of allicin. According to an MTT assay, the rate of cell proliferation was inhibited, thus suggesting that tumor growth was significantly inhibited. Furthermore, when the MGC-803, BGC-823 and SGC-7901 cells were treated with $1 \mu \mathrm{g} / \mathrm{ml}$ allicin for 12 , 24 and $48 \mathrm{~h}$, the rate of cell proliferation was also reduced. These results suggest that the proliferation of human gastric carcinoma cells was inhibited by allicin in a dose- and time-dependent manner. In addition, Hoechst staining demonstrated increased apoptosis of the MGC-803 cells following treatment with $1 \mu \mathrm{g} / \mathrm{ml}$ allicin for $48 \mathrm{~h}$. There are two main classic cell apoptosis signaling pathways (19): The death receptor pathway, which is mediated by the Fas/FasL pathway; and the mitochondrial pathway, which initiates downstream caspase cascade activation. These two pathways mediate apoptosis through the common caspase pathway. Caspase 3 is a member of the caspase family, which has a key role in apoptosis (20). The present study analyzed the expression levels of apoptosis-associated proteins by western blotting. In response to an increased concentration of allicin, the intracellular protein expression levels of cleaved caspase 3 were significantly increased in the MGC- 803 cells, thus suggesting an increased rate of cell apoptosis.

Previous research has shown that the activation of intracellular p38 MAPK is often accompanied by activation of caspase 3 , which then induces the apoptotic caspase cascade $(14,21)$. Therefore, the present study further analyzed the protein expression levels of p38 MAPK in MGC-803 cells. In response to treatment with an increased concentration of allicin, the intracellular protein expression levels 
of p38 MAPK were increased. Furthermore, the rate of cell apoptosis was determined by flow cytometry, using an Annexin V-FITC-PI kit. Based on the flow cytometry results, the rate of apoptosis was increased, when the concentration of allicin was increased from 0.1 to $10 \mu \mathrm{g} / \mathrm{ml}$. These results suggest that the $\mathrm{p} 38 \mathrm{MAPK} / \mathrm{caspase} 3$ pathway has an important role in the effects of allicin on gastric cancer cell apoptosis.

In conclusion, the results of the present study demonstrate that allicin can inhibit the proliferation and induce apoptosis of human gastric cancer cells. The underlying mechanisms may involve activation of the p38 MAPK signaling pathway and hydroxylation of caspase 3 . As compared with other chemotherapeutic drugs, allicin is characterized by low levels of toxicity and few side effects. As a promising chemotherapeutic drug, the elucidation of allicin's molecular mechanism will have significant effects in tumor prevention and treatment

\section{References}

1. Zhang W, Ha M, Gong Y, Xu Y, Dong N and Yuan Y: Allicin induces apoptosis in gastric cancer cells through activation of both extrinsic and intrinsic pathways. Oncol Rep 24: 1585-1592, 2010.

2. Ha MW and Yuan Y: Allicin induced cell cycle arrest in human gastric cancer cell lines. Zhonghua Zhong Liu Za Zhi 26: 585-589, 2004 (In Chinese).

3. Park SY, Cho SJ, Kwon HC, Lee KR, Rhee DK and Pyo S: Caspase-independent cell death by allicin in human epithelial carcinoma cells: involvement of PKA. Cancer Lett 224: 123-132, 2005.

4. Zhang YW,Eom SY, Yim DH, et al: Evaluation of the relationship between dietary factors, CagA-positive Helicobacter pylori infection, and RUNX3 promoter hypermethylation in gastric cancer tissue. World J Gastroenterol 19: 1778-1787, 2013.

5. Sato T, Kikuchi Y, Saito T, Hirano S and Kouzuma T: Results of chemotherapy using new anti-cancer drugs since S-1 for advanced or recurrent gastric cancer in our institute. Gan To Kagaku Ryoho 34: 1819-1825, 2007 (In Japanese).

6. Tyagi G, Pradhan S, Srivastava T and Mehrotra R: Nucleic acid binding properties of allicin: spectroscopic analysis and estimation of anti-tumor potential. Biochim Biophys Acta 1840: 350-356, 2014.

7. Hirsch K, Danilenko M, Giat J, et al: Effect of purified allicin, the major ingredient of freshly crushed garlic, on cancer cell proliferation. Nutr Cancer 38: 245-254, 2000.
8. Chu YL, Ho CT, Chung JG, Rajasekaran R and Sheen LY: Allicin induces p53-mediated autophagy in Hep G2 human liver cancer cells. J Agric Food Chem 60: 8363-8371, 2012.

9. Osman M, Adnan A, Salmah Bakar N and Alashkham F: Allicin has significant effect on autoimmune anti-islet cell antibodies in type 1 diabetic rats. Pol J Pathol 63: 248-254, 2012.

10. Liang X, Yang Y, Deng C, et al: The variation of Caspase3 activity in tanshinone induced NB4 cells apoptosis. Sichuan Da Xue Xue Bao Yi Xue Ban 34: 549-551, 2003 (In Chinese).

11. Guo L, Dong F, Hou Y, Cai W, Zhou X, Huang AL, Yang M, Allen TD and Liu J: Dihydroartemisinin inhibits vascular endothelial growth factor-induced endothelial cell migration by a p38 mitogen-activated protein kinase-independent pathway. Exp Ther Med 8: 1707-1712, 2014.

12. Feidantsis K, Pörtner HO, Markou T, Lazou A and Michaelidis B: Involvement of p38 MAPK in the induction of Hsp70 during acute thermal stress in red blood cells of the gilthead sea bream, Sparus aurata. J Exp Zool A Ecol Genet Physiol 317: 303-310, 2012.

13. Franks HA, Wang Q, Lax SJ, et al: Novel function for the p38-MK2 signalling pathway in circulating CD1c+ (BDCA-1+) myeloid dendritic cells from healthy donors and advanced cancer patients; inhibition of p38 enhances IL-12 whilst suppressing IL-10. Int J Cancer 34: 575-586, 2013.

14. Jameel NM, Thirunavukkarasu C, Wu T, Watkins SC, Friedman SL and Gandhi CR: p38-MAPK- and caspase-3-mediated superoxide-induced apoptosis of rat hepatic stellate cells: reversal by retinoic acid. J Cell Physiol 218: 157-166, 2009.

15. Andualem B: Combined antibacterial activity of stingless bee (Apis mellipodae) honey and garlic (Allium sativum) extracts against standard and clinical pathogenic bacteria. Asian Pac J Trop Biomed 3: 725-731, 2013.

16. Mozaffari-Khosravi H, Hesabgar HA, Owlia MB, Hadinedoushan H, Barzegar K and Fllahzadeh MH: The effect of garlic tablet on pro-inflammatory cytokines in postmenopausal osteoporotic women: a randomized controlled clinical trial. J Diet Suppl 9: 262-271, 2012.

17. Li L, Sun T, Tian J, Yang K, Yi K and Zhang P: Garlic in clinical practice: an evidence-based overview. Crit Rev Food Sci Nutr 53: 670-681, 2013.

18. Pittler $\mathrm{MH}$ and Ernst E: Clinical effectiveness of garlic (Allium sativum). Mol Nutr Food Res 51: 1382-1385, 2007.

19. Zhou Y, Wang Q, Evers BM and Chung DH: Signal transduction pathways involved in oxidative stress-induced intestinal epithelial cell apoptosis. Pediatr Res 58: 1192-1197, 2005.

20. Simpson KL, Cawthorne C, Zhou C, et al: A caspase-3 'death-switch' in colorectal cancer cells for induced and synchronous tumor apoptosis in vitro and in vivo facilitates the development of minimally invasive cell death biomarkers. Cell Death Dis 4: e613, 2013.

21. Boosani CS, Nalabothula N, Munugalavadla V, et al: FAK and p38-MAP kinase-dependent activation of apoptosis and caspase-3 in retinal endothelial cells by alpha1 (IV) NC1. Invest Ophthalmol Vis Sci 50: 4567-4575, 2009. 